Recibido: 11/03/2016

Aprobado versión definitiva: 14/05/2016

\title{
MOVIMIENTOS SOCIALES Y PARTIDOS POLÍTICOS ANTE PROCESOS DE CAMBIO: UN DEBATE TEÓRICO A LA LUZ DE LA EMERGENCIA DEL MAS
}

IGNACIO GARCÍA MARÍN ${ }^{1}$

\section{RESUMEN}

La presente investigación lleva a cabo un análisis teórico sobre el rol que partidos políticos y movimientos sociales desempeñan durante los procesos de cambio social y político y sus relaciones. En este sentido, las diferencias en cuanto a organización, campo de juego o medios les permiten desempeñar roles en ocasiones complementarios pero frecuentemente antagonistas. Ejemplo de ello, se presenta la experiencia del Movimiento al Socialismo (MAS) en Bolivia como ilustración de los límites y oportunidades que los movimientos sociales y partidos políticos representan, especialmente notorios en coyunturas críticas y contextos donde las instituciones formales tienden a mostrar resistencia al cambio.

Palabras Clave: movimientos sociales; partidos políticos; cambio social; coyuntura crítica; MAS.

\footnotetext{
${ }^{1}$ Magíster en Derecho Constitucional del Centro de Estudios Políticos y Constitucionales (España) y Candidato a doctor en el programa de excelencia Gobierno y Administración Pública del Instituto Ortega y Gasset (España). C/ Fortuny, 53. Código postal: 28010, Madrid, España Afiliado con El Colegio de México -COLMEX- (México). Correo electrónico: nachogarciamarin@yahoo.es.
} 


\section{SOCIAL MOVEMENTS, POLITICAL PARTIES AND THE PROCESSES OF CHANGE: A THEORETICAL DEBATE IN LIGHT OF THE EMERGENCE OF MAS}

\section{ABSTRACT}

This research takes place a theoretical analysis of the role that political parties and social movements play during the processes of social and political change and their relations. In this respect the differences in organization, scope of action or ways, allow them to play complementary roles but often antagonistic behavior. In this sense, the experience of the Movimiento al Socialismo (MAS) in Bolivia is an illustration of the limits and opportunities that social movements and political parties represent, especially noticeable at critical junctures and contexts where formal institutions tend to show resistance to institutional change.

Keywords: social movements; political parties; social change; critical juncture; MAS.

\section{Introducción}

Durante las últimas décadas se ha asistido a intensos cambios sociales y políticos a lo largo del mundo. El desmoronamiento del bloque comunista europeo, las crisis económicas en América Latina en la década de los años 80 y a principios de los 2000 o la actual crisis en Europa, han traído consigo incrementos de la desigualdad de ingreso, del desempleo y de la distancia entre ciudadanos y el régimen político imperante. Ante estos cambios, que podrían ser englobados especialmente en las esferas social, económica y política, parte de la ciudadanía ha tendido a organizarse en movimientos sociales como vía de expresar su rechazo a ciertas medidas emprendidas desde sus gobiernos pero, a la vez, para presentar sus demandas de forma explícita y alternativa a los medios institucionales convencionales. En este sentido, tanto América Latina como Europa han jalonado estas décadas con nuevas organizaciones sociales y de muy diversa índole. Medio ambiente, género, igualdad real, indigenismo, altermundismo y antineoliberalismo son sólo unas de las pocas etiquetas que podrían calificar a los 
cientos de movimientos sociales que han ido apareciendo y que, en variados casos, han logrado total o parcialmente sus objetivos. No obstante, su aparición y/o consolidación podría denotar al mismo tiempo una incapacidad de ciertas instituciones políticas de asumir, entender e implementar medidas a tenor de las demandas sociales que parte de sus sociedades presentan. En este sentido, los partidos políticos, especialmente aquellos que conformaran la membresía de los órganos de gobierno y parlamento, serían los más señalados en esta posible falencia de adaptación, cooptación o simple distanciamiento ante la ciudadanía.

Sin embargo, el desempeño de las organizaciones colectivas, ya sean movimientos sociales o partidos políticos, podrían verse en gran medida afectados por la coyuntura que se atravesara. $O$, dicho de otro modo, aparentemente la situación socio-política podría influir en la interrelación y equilibrio de fuerzas entre estos actores (García y Rodríguez, 2015). Es precisamente aquí donde podrían entrar en juego no ya únicamente las coyunturalidades y momentos de crisis, sino la capacidad que los distintos actores posean para desplegar distintas interpretaciones, significaciones o definiciones sobre las realidades que están en juego. En este sentido, se propone una reflexión en torno a los movimientos sociales y los partidos políticos a raíz de sus principales características desde una perspectiva teórica, pero trayendo a colación la aparición y emergencia del Movimiento al Socialismo (en adelante MAS) boliviano a modo de ilustración. Aparentemente, esta organización colectiva, conformada en cierto modo como 'partido de movimientos o de diversas organizaciones sociales' desplegó una doble vía para la consecución de sus objetivos: compitiendo por un lado por la vía electoral $y$, por el otro, formando parte directa o indirectamente en variados conflictos, crisis e hitos sociales donde la ciudadanía protestó ante diversas autoridades públicas y privadas ante medidas que entendían iban en contra de sus derechos y/o demandas. Es posible a su vez que esta asistencia a la lucha social desde vías no institucionales granjeara cercanía y capacidad de entendimiento al MAS ante el cambio social que el país estaba viviendo. Ello, sumado a la pérdida de representatividad de los hasta entonces principales partidos políticos del país, pudo generar junto a la 
coyunturalidad crítica del ciclo rebelde (2000-2005) una ventana de oportunidades políticas.

\section{Revisión bibliográfica en torno a los movimientos sociales}

Si bien podría decirse que los partidos políticos han sido uno de los grandes protagonistas de la democracia desde la segunda mitad del siglo XIX (Bravo, 2002), no debiera minusvalorarse el rol que los movimientos sociales han jugado desde entonces. El planteamiento de demandas de corte social o el empoderamiento de las mujeres en libertad e igualdad respecto al hombre, son ejemplos de demandas donde los movimientos sociales resultaron ser clave para su paulatino reconocimiento.

Aunque ambas formas de actuación política guardan ciertas diferencias posiblemente irreconciliables y las relaciones entre ambas pueden ser en ocasiones distantes, tanto los partidos políticos como los movimientos sociales han sabido obtener réditos político-sociales de sus actuaciones.

Respecto a estos últimos, podría definirse a un movimiento social, como una

Red de relaciones informales entre individuos, grupos y organizaciones que, en sostenida y frecuentemente conflictiva interacción con autoridades políticas y otras élites, y compartiendo una identidad colectiva no necesariamente excluyente, demandan públicamente cambios (potencialmente antisistémicos) en el ejercicio o redistribución del poder en favor de intereses cuyos titulares son indeterminados e indeterminables colectivos o categorías sociales. (Ibarra, 2005, p.94)

Esta definición denotaría ciertas características propias de los movimientos sociales. Sirvan de ejemplo la conflictiva relación entre movimientos sociales y actores políticos institucionales o el potencial entramado de redes que en ocasiones forman los movimientos sociales. En todo caso, como señalara McAdam (1982)

A movement represents a continuous process from generation to decline, rather than a discrete series of developmental stages. Accordingly, any complete model of social insurgency should offer the researcher a framework for analyzing the entire process of movement development rather than a particular phase. (p.36) 
En este sentido, podría entenderse que el ciclo de vida de los mismos representaría cierta irregularidad, quizá motivada por la tendencia al planteamiento de muy concretas demandas o de las incapacidades de transformación y cambio que denotaría la protesta basada en cauces no institucionales. Recuérdese en este punto que asimismo existiría una muy variada gama de estabilidad de los mismos, habiendo movimientos sociales de escasa duración, pero con otros de larga data, incluyendo a ciertas organizaciones que terminaron convirtiéndose con éxito electoral en partidos políticos, caso del MAS boliviano o del Die Grüne alemán.

Respecto a otras características que singularizarían a los movimientos sociales, Ibarra (2005, pp.85-86) señala una cualidad que podría resultar de interés a la hora de generar, plantear y defender imaginarios alternativos, ya que el autor resalta que estos actores son "también un proceso de construcción de una identidad colectiva". Asimismo, los medios empleados para la presentación de sus demandas y para obtener concesiones y reconocimiento por parte de los actores políticos institucionales, es sin duda un factor esencial para caracterizar a los movimientos sociales. Dichos medios, a menudo catalogados de no convencionales, han sido variados a lo largo del tiempo y del espacio, contando con un elevado y rico repertorio de acción que incluiría desde el corte de carreteras y calles espontáneos, hasta las manifestaciones acordadas y legales, el ataque de ciertas infraestructuras consideradas por los protestantes como dañinas o la ocupación de tierras de cultivo. Sin embargo, más importante que la amplia gama del repertorio de acción con el que cuentan los movimientos, habría que destacar la preferencia de estas organizaciones por obtener respaldo popular y niveles mínimos de legitimidad social ante el poder político (Ibarra, 2005, pp.88). Ello podría producirse debido a que, si bien los movimientos sociales no tienen capacidad para incidir de forma directa en el juego electoral e incluso institucional, sí pueden tratar de lesionar la base electoral y popular de los partidos políticos, y de ahí su prioridad social antes que partidista. 
Ahora bien, si se tratara de hacer una breve caracterización de los movimientos sociales, especialmente desde un punto de cronológico y de demandas planteadas, surgirían diversas respuestas y cuestionamientos derivados de ello. Por ejemplo, ha tendido a denominarse a los primeros movimientos sociales, tales como las agrupaciones obreras y de corte nacionalista de movimientos sociales viejos, situándolos en los albores del siglo XIX. Décadas después, tras la Segunda Guerra Mundial y con el desarrollo de las economías capitalistas y democráticas de Europa occidental y Norteamérica, se produjeron cambios sociales y demográficos y, posiblemente resultado de ello, nuevas demandas y movimientos sociales. Véase el caso del pacifismo, ecologismo, igualdad racial (especialmente en Estados Unidos) o demandas protagonizadas por estudiantes a ambos lados del Atlántico.

No obstante, las posteriores décadas propiciarían la emergencia primero, de "movimientos sociales novísimos" (siguiendo a Ibarra, 2005) basados en valores en torno a la solidaridad, la cooperación internacional o el antirracismo. Actualmente, y con la progresiva globalización facilitada por el hundimiento del bloque socialista y la aparición de tecnologías como Internet y la facilitación del movimiento e intercambio de ideas, personas y mercancías, se producirían movimientos de carácter anti-globalización. Dichos movimientos no debieran entenderse únicamente desde una perspectiva 'anti', sino también alternativa al actual proceso globalizador. En todo caso, se desea destacar que, si bien esta breve cronología mostraría el sostenimiento de la protesta social y de las organizaciones sociales a lo largo de las décadas, no siempre podría hablarse de nuevas demandas y de fácil encasillamiento de los movimientos sociales. Recuérdese a los movimientos feministas o a los de carácter nacionalista.

Empero, podría decirse que habría una tendencia o intención de transformación social, donde no resultaría sencillo la clasificación de estas organizaciones, ya que "dependiendo de la coyuntura, demandas y éxitos, podrían ser viejos movimientos sociales o nuevos movimientos sociales" (Ibarra, 2005, p.89). Por tanto, puede concluirse a este respecto que si bien tanto el repertorio de 
acción, como las causas han tendido a variar a lo largo de las décadas, existirían ciertas causas socio-políticas que se mantienen en el tiempo (género, clase, nación) y que, en cierto modo, esta estabilidad en la demanda lesionaría la presumible coyunturalidad que se tiende a asignar a los movimientos sociales. No obstante, como a continuación se mostrará, sí podría incidir el contexto en sentido amplio en las capacidades de éxito de las demandas planteadas.

21. La importancia del contexto: ¿la coyunturalidad como factor relevante para surgimiento y/o consolidación?

Por tanto, pareciera que si bien ciertas demandas -o grupos de demandasse mantienen en el tiempo, otras emergen con el cambio social, cultural y/o económico y, a su vez éstas se ven influidas por el equilibrio en las relaciones de poder existente entre los principales actores políticos. Podrían a su vez plantearse preguntas en torno al por qué y cuándo emergen los movimientos sociales, así como qué condiciones y factores propiciarían su éxito. Ciertamente, estas cuestiones son de difícil respuesta, aunque una vía de aproximación podría tratarse a través de la teoría de la Estructura de Oportunidades Políticas.

Ventura (2007, pp.35-36) señala este enfoque centra su atención en el entorno institucional y político en el que se produce la acción colectiva, especialmente en el análisis de la influencia del contexto político en la formación y supervivencia de los movimientos sociales. La mayoría de los trabajos académicos que empezaron a proponer este enfoque en los setentas, entre los que se encuentran los de Gamson, Tilly, Piven y Cloward y McAdam buscaban explicar cómo cambios específicos en aspectos del sistema político crean nuevas oportunidades para la acción colectiva de un actor o un grupo de actores que lo desafían. A este respecto, podría añadirse lo apuntado por Caren (2007) "focuses on the interaction between movement attributes, such as organizational structure, and the broader economic and political context" $(p, 1)$. 
Hay pues, un enfoque en el contexto social, económico y político que propiciaría o, al menos facilitaría, la aparición, fortalecimiento y visibilidad de ciertos movimientos sociales. Huelga decir que si bien estas afirmaciones guardarían cierta obviedad, no habría de olvidarse que se estaría, de manera indirecta, generando una visión donde ciertos actores políticos ${ }^{2}$ mostrarían ciertas limitaciones para la adaptabilidad de nuevas demandas en entornos cambiantes así como para la canalización de deseos y planteamientos en momentos de crisis. Podría entenderse pues, que ante la emergencia de movimientos y organizaciones sociales, los partidos políticos tendrían más que perder que ganar, al encontrar cierta competencia para la disputa del control de la respuesta ante la demanda ciudadana y, sobre todo, ante la generación de idearios, interpretaciones e imaginarios alternativos a los vigentes. Todo ello, sin olvidar que ambas formas de organización política disputan formalmente distintos escenarios, pero donde potencialmente la no atención o capacidad de asumir demandas -sean éstas nuevas o no- podrían no sólo lesionar los intereses electorales de los partidos, sino además obtener nuevos competidores, siendo los anteriormente mencionados MAS y Die Grüne ejemplos de ello. O, por qué no decirlo, el reciente caso de Podemos o los numerosos movimientos y organizaciones sociales que por casi toda la geografía española se movilizaron en los últimos meses de la segunda legislatura de Rodríguez Zapatero en una amalgama de demandas y propuestas de cambio. Algunas de ellas posiblemente ya defendidas o cooptadas por partidos ya establecidos pero que significaron, afianzaron o reforzaron la visión en algunos ciudadanos y actores sociales de que no se sentían representados por los principales partidos políticos ya existentes así como por el régimen político a nivel general.

En todo caso, y volviendo sobre la estructura de oportunidades políticas, podría decirse que algunos autores como Tilly vinculan

\footnotetext{
${ }^{2}$ Piénsese por ejemplo en partidos políticos o instituciones del Estado, las cuales en un entorno de crisis económica aparentemente tendrían dificultades para responder de forma efectiva a parte de los reclamos planteados desde la sociedad.
} 
La acción colectiva con el Estado mediante dos dimensiones principalmente: la oportunidad/amenaza para los grupos movilizados y la facilitación/represión por parte de las autoridades. Así, lo que explica la existencia, alcance o ausencia de movilización es el costo de la "acción colectiva", que aumenta por la represión o disminuye por la facilitación. (Ventura, 2007, pp.35-36)

Dicho costo, se enfrentaría con el enroque o conservadurismo de las clases dirigentes, donde los principales partidos políticos, especialmente aquellos de carácter oficialista o gubernamental, estarían incluidos. Como advierte McAdam (1982, p. 38) la clase política "resist changes which would threaten their current realization of their interests even more than they seek changes which would enhance their interests" (McAdam,1978, p.135; citado en McAdam, 1982, p.38). Sería no obstante interesante advertir que este escenario de oportunidades, donde se propiciaría la aparición de nuevas organizaciones y demandas, así como de su posible éxito, no tendría porqué resultar evidente. Si bien en el caso que aquí se mencionará posteriormente para la discusión en torno a los movimientos sociales se enmarcaría en un escenario de fuerte tensión social y complicado escenario económico, no siempre resultaría un escenario tan crítico para la conformación de un tablero tan aparentemente idóneo para la protesta social. En este sentido, Tarrow (1998) señala al respecto que

Las oportunidades políticas pueden no resultar aparentes a primera vista para todos los potenciales participantes de la acción colectiva, De hecho una de las ventajas que aporta el concepto es que nos ayuda a comprender el modo en que las movilizaciones se contagian a partir de grupos con profundos agravios y abundantes recursos a otros con menores quejas y recursos. (p.117)

Esto asimismo podría relacionarse con la percepción por parte de los miembros del movimiento social de una carencia o serie de carencias que justificarían la protesta. Ibarra (2005) señala que estas privaciones o sensaciones de necesidad podrían catalogarse como estructurales, organizativas o culturales. En relación al caso español ya anteriormente comentado, la difícil situación que el país enfrentó desde el pinchazo de la burbuja inmobiliaria, así como de la política económica desplegada en concordancia con los restantes estados europeos, pudieron generar una serie de tensiones laborales, sociales y económicas que 
propiciaran la protesta social (Estrada, 2015). Asimismo, y siguiendo la definición de Ibarra respecto a este tipo de carencias "un movimiento social surge porque otras formas preexistentes de solucionar ese conflicto no pueden llegar a él, no saben llegar a él o no quieren llegar a él. Surge pues, porque existen carencias organizativas" (Ibarra, 2005, p.119). Por tanto, aun no deseando entrar en detalle, el contexto socio-económico, así como el desempeño de los partidos políticos existentes y su visión en parte de la sociedad, podrían explicar, al menos mínimamente, tanto el ciclo de protestas mencionado, como la deslegitimación de los principales partidos políticos y de su capacidad de absorber las demandas, simpatías y voto de ciudadanos. O, dicho de otro modo, el MAS pudo ser una respuesta "esperada" bajo este escenario.

No obstante, si bien ante las crisis y momentos de cambio los movimientos sociales tendrían una suerte de ventana de oportunidad, esto en cierto modo iría en detrimento de los partidos políticos. No tanto por la competencia para representar y/o cooptar demandas -y demandantes- sino además porque denotaría cierta rigidez tanto de ellos mismos como de las propias instituciones del Estado. Por ello, se entiende necesario un abordaje mínimo a la relación entre movimientos sociales y partidos políticos.

22. La relación entre partidos políticos y movimientos sociales

Los partidos políticos en principio son quienes ostentan el monopolio de la actuación política por la vía electoral y, con ello, a un acceso privilegiado -pero no monopólico- a las instituciones legislativas y ejecutivas. Una breve pero adecuada definición podría ser la dada por La Palombara y Weiner, quienes establecen que un partido político consistiría en

una organización duradera, cuya esperanza de vida sea superior a la de sus dirigentes. Estable, dotada de relaciones regulares y diversificadas. Una voluntad deliberada de los dirigentes locales y nacionales para tomar y ejercer el poder solos o en coalición- y no sólo de influir sobre él. (La Palombara y Weiner, 1966, p.35 citado en Vela, 2008, p.153) 
Una definición posiblemente más crítica sería la dada por Downs para quien un partido político se trataría de "un grupo poco coherente de personas que cooperan principalmente con el fin de que alguno de sus miembros ocupe cargos en el gobierno" (Downs, 197, p.26 citado en Vela, 2008, p.164). No obstante, y en relación a los movimientos sociales, añádase que "un partido político tiene vocación de ejercer el poder político. Un movimiento social demanda al poder político que establezca determinados cambios en la sociedad" (Ibarra, 2005, p.83). En todo caso, como señala Stokes (1999, p.1): "Los partidos políticos son endémicos a la democracia. Sin embargo, no forman parte de ninguna definición formal de aquélla; ni las constituciones de la mayoría de las democracias establecen un rol para los partidos.

No obstante, si bien con los movimientos sociales se ha establecido en la sección previa una cronología histórica destacando los principales valores que defendían según la época, con los partidos políticos, más que de distintas demandas, debiera hablarse de diferentes maneras de organizarse $y$, especialmente, de abordar la contienda electoral. En este sentido, y dejando de lado las familias espirituales o ideológicas que en su día hiciera Klaus Von Beyme, en un principio los partidos políticos nacieron como agrupaciones o cuadros de élites (Duverger, 2002). Esta caracterización, la cual respondería en parte al notable sufragio restringido existente durante los comienzos del XIX daría paso décadas después a los partidos de masas (Boudon, 1996), ejemplificados en el Sozialdemokratische Partei Deutschlands alemán (SPD) como partido capaz de movilizar grandes colectivos sociales y, con ello, la representación y canalización de demandas, especialmente de corte social e izquierdista. Esta evolución, que respondió en parte a la paulatina democratización de los regímenes liberalconstitucionales del siglo XIX conllevó una evidente participación creciente de votantes. Interesante sería reseñar aquí la relación existente entonces entre movimientos sociales, sindicatos y ciertos partidos políticos en pos de la defensa de ciertos valores comunes. Derechos laborales y sociales, especialmente. 
Posteriormente, y ya tras la segunda guerra mundial, nacerían los denominados partidos atrapa-todo o catching-all, denominados así por una progresiva pérdida de ideologización y de sus postulados al tratar de obtener votos de variados perfiles de electores. En todo caso, y dejando de lado esta evolución o cambio a lo largo de las décadas en la organización y estrategia de los partidos políticos, destáquese a las organizaciones partidistas atrapa-todo (o una posterior evolución en partidos cártel) por ser quienes tienden a obtener las mayores cuantías de votos en los sistemas políticos actuales y, posiblemente, porque en el caso de las fuerzas socialdemócratas, la victoria de sus demandas y establecimiento de su modelo propugnado les convirtió en una suerte de fuerzas conservadoras. Esta situación no resultaría baladí, pues por un lado podría entenderse que el atendimiento de demandas de marcado tono centrista ideológico podría dejar huérfanos de referencia partidista a quienes no se ubiquen en esos valores. Pero, además, porque el establecimiento de sistemas de bienestar, especialmente en centro y norte de Europa resultaría en determinadas fuerzas políticas una actitud conservadora ante el cambio y reforma de lo hasta entonces obtenido, generando con ello ciertos distanciamientos de ciudadanos no conformes con estas actitudes ${ }^{3}$.

Si bien podrían ser discutibles estas aseveraciones, algunos autores se han referido a los cambios en las relaciones entre la sociedad y los partidos políticos de situación de crisis, dados sus menguantes niveles de afiliación o de confianza ciudadana en ellos (Puhle, 2007 citado en Daza, 2014, p.315). Ventura por ejemplo destaca los desafíos que deben enfrentar "desde arriba por el debilitamiento del Estado como referente de la acción social, (...) desde el medio por los propios problemas de reorganización del sistema partidista y (...) desde abajo, por las nuevas organizaciones y movimientos que parecen debilitar su papel en la sociedad." (Ventura, 2007, p.52). Boudon (1996, p.29) asimismo, destaca la

\footnotetext{
${ }^{3}$ Me refiero al hecho de que pudiera entenderse de manera razonable que los partidos políticos de corte socialdemócrata en ciertos países del norte de Europa lograron imponer su modelo de Estado en el más amplio sentido del mismo, por lo que, tras ello, su política pública e incluso su discurso, tendió a ser razonablemente conservador.
} 
incapacidad que los partidos políticos han mostrado en su función de enlace entre ciudadanía y Estado, idea elaborada por Lawson y que establecería "cuatro tipos de linkage que son separados, pero no mutuamente exclusivos, que utilizan los partidos políticos: participativo, electoral, clientelista, y directivo" (Lawson, 1988, p.16 citado en Boudon, 1996, p.29).

No obstante, contrarios a esta idea de crisis de los partidos políticos, serían autores como Mair, quien indica que "no están en crisis, sino que se trata de una de sus tres "facetas" (el partido de base). Las otras dos facetas el partido en la oficina pública (elegida) y la organización central se han vuelto profesionales y, entonces, están más aisladas de sus constituyentes" (Boudon, 1996, p.30).

A lo que Boudon (1996) añade que "los partidos políticos, por eso, tal vez no se encuentran en estado de declive, sino en un proceso de cambio. Los votantes, sin embargo, están dejando saber, de una manera u otra, que no están contentos con estos cambios" (p.30). Bajo este punto de vista, los sistemas de partidos se enmarcarían en procesos de cambio, especialmente los situados en modelos proporcionales parlamentarios, dándose una lucha entre nuevos y viejos partidos y, a su vez, cuestionando el statu quo o relación de poderes entre fuerzas partidistas.

Respecto a este proceso de cambio y competitividad, y trayendo a colación aquellos contextos ya mencionados en el anterior epígrafe sobre movimientos sociales, algunos autores como Boudon (1996) señalan que "los partidos establecidos, de cualquier tipo, muchas veces son incapaces de ajustarse a las crisis, bien porque la crisis es demasiado severa, o porque no están bien dotados para adaptarse a las circunstancias cambiantes" (Boudon, 1996, p.31). Esta ventana de oportunidades, en un difícil contexto socio-económico con amplificaciones a la arena política, podría por tanto generar oportunidades no ya sólo a los movimientos sociales como anteriormente se mencionó, si no que perturbaría el sistema de partidos, poniendo en cuestión las relaciones de poder pre-existentes y generando, quizá, la oportunidad a nuevas organizaciones políticas colectivas. En este sentido, resáltese la siguiente afirmación de Boudon 
(1996, p.31): "Una crisis de partidos o sistemas, entonces, parece ser la condición necesaria para la aparición de nuevos partidos políticos". Y esta generación de nuevos partidos, podría asimismo propiciar nuevas relaciones entre ciudadanos y partidos políticos, tesis que no obstante sería difícil de sostener debido al no muy acelerado proceso de conformación y sustitución de los partidos políticos y a distintos obstáculos y desventajas que potencialmente pueden enfrentar las nuevas formaciones partidarias. Véase el caso de recursos económicos y humanos, o diferentes leyes electorales y de aparición en medios de comunicación.

Por ello, esta visión de renovación y lucha por la supervivencia entre partidos políticos debiera considerarse con cierta perspectiva, al menos en lo que a su comparativa con movimientos sociales se refiere, o a la propia dominación electoral de fuerzas políticas del arco parlamentario en países como España. No obstante, y quizá como ejemplo de esta ventana de oportunidades políticas, desconfianza sobre los partidos políticos pre-existentes y aparición de nuevas fuerzas partidarias podría encontrarse el caso de la reciente formación Podemos, la cual encajaría razonablemente en estas líneas previas de efecto ante demandas planteadas desde la sociedad civil y no satisfactoriamente asumidas por otros partidos políticos y emergencia electoral por un mayor enlace con parte de la ciudadanía. Así pues, se podría dar la razón a Duque Daza cuando afirma que "el énfasis en la tesis del debilitamiento de los vínculos con la sociedad, en los problemas de deslegitimación y desafección, tiende a desconocer que también hay nuevos partidos y nuevos partidismos, que hay otras agrupaciones que han logrado insertarse en la competencia y han desarrollado formas novedosas de relación con la población" (Daza, 2014, p.315). Por tanto, más que despartidización de la sociedad, quizá debiera en ocasiones hablarse de una nueva partidización (Ibídem).

No obstante, si pudiera hablarse, al menos superficialmente y de forma preliminar, de una cierta causa-efecto en la generación de nuevas demandas, movimientos sociales y partidos políticos, debiera al menos mencionarse qué 
posibles relaciones se pueden establecer entre ambas organizaciones políticas. En este sentido, Ventura (2007, pp.41-48) señala cinco vías principales de relación: articulación, permeabilidad, alianza, independencia y transformación. De la primera de ellas, el autor señala que consistiría en que "los movimientos sociales se agrupan alrededor del programa de un partido político y promueven las posiciones partidistas entre los seguidores potenciales a los que los partidos esperarían movilizar en busca de apoyo y de nuevos miembros. Aun cuando los partidos políticos controlan directamente a estas organizaciones, generalmente éstas ejercen alguna influencia independiente sobre el partido" (Ventura, 2007, p.41).

Respecto a la permeabilidad, se daría cuando "las organizaciones del movimiento social infiltran a los partidos para intentar orientarlos hacia su causa. Para tener posibilidades de éxito, esta estrategia presume que existe un apoyo considerable a las causas del movimiento dentro del partido político" (Ventura, 2007, p.42). Así, la alianza se trataría de acuerdos

ad hoc con partidos o facciones de partidos que involucren la colaboración cercana en asuntos específicos, pero en las que tanto el partido como la organización retienen su propia estructura separada y libertad general de acción. Las coaliciones o alianzas implican que cada parte espera obtener beneficios específicos y concretos; éstas se disuelven si estas expectativas no se cumplen. (Ventura, 2007, p.43)

La relación de independencia por su parte entre movimientos sociales y partidos políticos se establecería cuando "las organizaciones del movimiento actúan autónomamente de los partidos políticos, presionándolos a hacer concesiones que, de no hacerse, pueden representar la pérdida de votos potenciales de quienes apoyan el movimiento." (Ventura, 2007, p.43). Finalmente, y quizá el más cercano a la situación expuesta anteriormente entorno a los movimientos sociales, escenario socio-político y la aparición de Podemos, la transformación, donde 
Los movimientos sociales se convierten en partidos políticos (...) importantes debates dentro de las organizaciones de los movimientos sociales y los partidos formados por éstos han surgido con relación a la posibilidad real de combinar los mecanismos electorales con los de los movimientos sociales; esto debido a que los movimientos se sienten más cómodos como 'partidos de protesta', pero obtienen más beneficios como 'partidos en el poder (Ventura, 2007, p.48).

\section{La reciente experiencia boliviana: emergencia del MAS y desplazamiento} de "lo viejo frente a lo nuevo"

Tras esta reflexión y descripción teórica en torno a los movimientos sociales, la estructura de oportunidades políticas y los partidos, podría traerse a colación el caso del MAS.

Este partido, el cual posee en la actualidad un importante dominio electoral a nivel nacional en Bolivia, llegó al Ejecutivo en 2006 bajo el liderazgo de Evo Morales. No obstante, su victoria no supuso únicamente un mero cambio en las más altas instituciones estatales a nivel legislativo y ejecutivo, sino que produjo una notable ruptura en el sistema de partidos hasta entonces vigente, así como la llegada de nuevas políticas públicas impregnadas de valores y cosmovisiones ciertamente marginadas con anterioridad. Asimismo, el análisis del MAS resultaría interesante dada la capacidad que mostró para aglutinar demandas y actores sociales extra-institucionales que fomentaron a posteriori un rediseño del Estado a través de la Constitucional Plurinacional de 2009. Su llegada al poder pues, materializó en cierto modo la lucha de planteamientos ideológicos y culturales alternativos que venían siendo defendidos desde tiempo atrás, pero que posiblemente un cambio de escenario socio-político, ayudó a su implementación y consolidación.

3.1. La crisis socio-política de Bolivia: el ciclo rebelde de 2000 a 2005

A continuación se pretenden mostrar, de una manera resumida, los principales hitos o protestas sociales que tendieron a una pérdida de legitimidad y estabilidad al régimen político boliviano. Asimismo, significó la emergencia o crecimiento de diversos movimientos sociales, los cuales, ante la incapacidad de 
las principales instituciones del país de asumir el cambio social que se estaba produciendo fueron cobrando mayor protagonismo. En este sentido destacarían el MAS y Evo Morales, dado el incremental protagonismo que irán tomando en la arena política boliviana.

Así, el contexto previo que marcó la victoria del MAS estuvo caracterizado por una serie de crisis político-sociales, una inestable situación económica y una creciente pérdida de legitimidad y apoyo social de las instituciones políticas, incluyendo los principales partidos. Esta etapa, de hecho, tendió a denominarse 'ciclo rebelde' y comprendió los años 2000 a 2005, dado el incremento cuantitativo y cualitativo de la protesta social a lo largo y ancho del país. En este sentido, se intensificó la toma de tierras, el corte de vías de acceso a las grandes ciudades o las sentadas ciudadanas con respecto a la década de los años 90. Ello, en un período donde los gobiernos bolivianos destacaron por su inestabilidad, creciente pérdida de apoyo social y la implementación de políticas económicas de corte neoliberal. Asimismo, a la par que Evo Morales y diversos colectivos obreros, indigenistas y campesinos cobraban protagonismo, lo hacían igualmente parte de sus discursos, significados y demandas. La nacionalización de empresas privatizadas años antes, la asunción de símbolos e idiomas indígenas, la implementación de políticas sociales o un mayor rol del Estado en la economía fueron posiblemente las grandes líneas del discurso alternativo y de ruptura que obtenía creciente respaldo en las calles. Algunos autores como Albó han definido estas protestas de "lucha contra un contexto neoliberal de matriz colonial" (Albó, 1993, p.20 citado en Cabezas, 2007), algo reseñable, ya que más que meras protestas encaminadas a imponer demandas y propuestas desde los movimientos sociales, se trataba de generar un nuevo modelo de país y de cosmovisión: multicultural, social, integrador y apoyado en nuevas mayorías, donde los colectivos subalternos se empoderaran. Suponía quizá, detener la lógica occidental y occidentalizante que caracterizaba al Estado boliviano desde su 
fundación hasta entonces ${ }^{4}$.

Fruto de esta protesta y la consecuente inestabilidad y pérdida de legitimidad del sistema político, durante este quinquenio hubo cuatro presidentes del gobierno y un notable desgaste e incluso desaparición de los partidos políticos hasta entonces dominantes: el Movimiento Nacionalista Revolucionario (MNR), el Movimiento Izquierda Revolucionaria (MIR) y la Acción Democrática Nacionalista (ADN). Valga de ejemplo la evolución electoral del MAS: fundado apenas en 1997, pasará del 20,9\% de votos en las presidenciales de 2002 al 53,72\% en 2005. Llamativo resultaría que, como han señalado diversos autores al comienzo de este ciclo rebelde, "no existían partidos de izquierda que defendieran de forma creíble los intereses de los sectores populares" (Zuazo, 2010, p.23), lo que en cierto modo pudo beneficiar la posterior eclosión del MAS.

Ahora bien, respecto a los principales hitos o eventos de protesta social que podrían destacarse en estos años, debieran citarse los siguientes:

En primer lugar la denominada 'Guerra del Agua' producida durante el año 2000 y con la ciudad de Cochabamba como principal escenario. Este evento, que duró menos de seis meses, escenificó una considerable oposición social a la gestión privada de las aguas en la ciudad, tornándose de manera incremental en una crítica al modelo económico que se implementaba desde la década de los años 80 (Suvelza, 2007). Sin entrar en detalles, esta crisis política permitió la confluencia de movimientos sociales y organizaciones civiles urbanas y rurales (Perreault, 2006, p.156) a raíz principalmente de un fuerte elevamiento de tarifas y una calidad de servicio cuestionable del agua (Ibídem). Tras meses de protestas y planteamientos de demandas, el gobierno retiró la concesión a Aguas del Tunari, perteneciente a una empresa de origen estadounidense, y creó un órgano administrativo a nivel local donde ciertos colectivos civiles tendrían cabida (Perreault, 2006, p.158). Debe destacarse la capacidad de diversos actores

\footnotetext{
${ }^{4}$ En este punto sería reseñable la política de descolonización interna, lógica que habría superado el discurso para traducirse en una resignificación del Estado y la nación bolivianas, pero además, tratando de subvertir las relaciones de poder que el país padecido desde la colonización en materia racial.
} 
procedentes de la sociedad civil de presentar demandas ante las instituciones y administraciones públicas y que éstas respondan en forma de cambio institucional. Máxime cuando se trataría, al igual que la posterior Guerra del Gas, de un período de relativa conflictividad social y de crítica ante privatizaciones realizadas con anterioridad.

Seguidamente, entre los años 2001 y 2002 los planes del ejecutivo boliviano de exportar gas natural hacia Norteamérica a través del Pacífico supusieron nuevamente un pico en la protesta social. Brevemente, la cuestión estribó entre la elección del puerto chileno de Mejillones o el peruano de Ilo, siendo la primera de ambas opciones la más rentable para las empresas adjudicatarias (Perreault, 2006, p.161) pero no así posiblemente en términos sociales para el ejecutivo, dado que el territorio chileno por el que el gas natural debía transcurrir fue durante gran parte del siglo XIX boliviano ${ }^{5}$. Dado que la propuesta por suelo chileno, apoyada por empresas como Repsol, British Gas o Pan-American Energy levantó quejas públicas por parte del ejército, grupos políticos y gran parte de la sociedad, ésta fue pospuesta por el presidente saliente Quiroga (Perreault, 2006, p.161). Esta crisis no sólo evidenció la posible distancia entre el Ejecutivo y parte de la sociedad, sino la propia pérdida de apoyos y legitimidad respecto a otras instituciones del Estado. A modo de ejemplo, el MAS de Evo Morales obtuvo un $20 \%$ de los votos en las presidenciales de 2002 , ubicándose segundo y a una distancia pequeña del ganador Sánchez de Lozada con el $22,5 \%$.

En tercer lugar se podría destacarse el conflicto político y social que se desarrolló principalmente en el mes de febrero de 2003 y que se debió a los planes del gobierno de Sánchez de Lozada de gravar los salarios con el fin de rebajar el déficit presupuestario en que el Estado estaba incurriendo (Espinoza y Gozálvez, 2003). Esta iniciativa, denominada 'impuestazo' por sus opositores, generó rápidamente un gran rechazo social, especialmente en núcleos urbanos como La Paz y El Alto y en el propio cuerpo de policía, el cual se convirtió en uno

${ }^{5}$ Territorio perdido tras la Guerra del Pacífico (1879-1883) ante Chile. 
de los principales sectores opositores a dicha medida gubernamental (Cotler, 2005). Lo reseñable de esta situación sería la fuerte oposición social ante los planes del gobierno, quien, tras semanas de considerable protesta ciudadana y dura respuesta de los cuerpos policiales y militares del Estado, tuvo que retirar dicha iniciativa, presentando el propio Sánchez de Lozada un plan alternativo para no reducir los salarios e incrementar la oferta pública de empleo (Espinoza y Gozálvez, 2003). Asimismo, esta crisis confirmó el ascenso producido desde los años 2000 y 2002 del Mas con Evo Morales como cabeza visible de la oposición (Cotler, 2005).

Destáquese asimismo la denominada 'Segunda Guerra del Gas', producida durante 2005 y que propició no sólo la sustitución del entonces presidente Carlos Mesa por Eduardo Rodríguez Veltzé, sino un adelanto electoral y la posible evidencia de que, a pesar de que los poderes políticos comenzaban a asumir parte de las demandas sociales, éstas no eran atendidas por completo y/o los actores implementadores no gozaban ya del necesario respaldo social. Sirvan de ejemplo la realización de un referéndum sobre la propiedad de los recursos hidrocarburíferos del país, así como la elevación de la carga impositiva por su extracción.

Estas y otras protestas se tradujeron en un notable desgaste para los principales partidos políticos, especialmente aquellos que contaban con cierta antigüedad o bien representaban imaginarios de lo viejo o previo, frente a los nuevos movimientos sociales y partidos políticos que se estaban articulando. Resultado de este momento de cambio sería la victoria contundente del MAS en diciembre de 2005 , alcanzando el $54 \%$ de los votos y, con ello, la presidencia del gobierno.

3.2. Resultados: nuevos actores, nuevos imaginarios. La victoria del MAS

Para entender la capacidad y tenacidad que el MAS mostró para llevar a cabo una transformación institucional, social e inclusiva del país, hay que entender antes la conformación del propio partido o, mejor dicho, de este ‘partido de 
movimientos y organizaciones sociales'.

Como señala Archondo (2007, p.85) los antecedentes más inmediatos del MAS debieran ser situados en 1995, año en el que es creada la Asamblea por la Soberanía de los Pueblos (ASP), de raigambre rural-sindical. Posteriormente, y por cuestiones electorales, se agruparon bajo las siglas de Izquierda Unida (IU), para finalmente optar por la actual denominación de Movimiento al Socialismo (MAS). Su membresía, especialmente campesina, comenzaría a obtener éxitos locales en la provincia de Chapare, perteneciente al Departamento de Cochabamba. A la par que este proceso de transformación de movimientos sociales, campesinos, indigenistas e izquierdistas se producía, se implementaba una reforma política que resultaría vital para el devenir futuro del liderazgo del MAS: la aprobación en 1997 de un nuevo sistema electoral de circunscripciones uninominales para la elección del $50 \%$ del Congreso. Esto propició por ejemplo que Evo Morales fuera el diputado más votado del país (Archondo, 2007, p.88) y, junto a su activismo, rostro emergente de la protesta social que comenzaba a incrementarse ante las instituciones del país.

En todo caso, habría que incidir en la estructura indirecta y horizontal de este partido de organizaciones sociales, donde, como Zuazo advierte "la afiliación al partido es una afiliación de las organizaciones sociales: indirectamente, los individuos miembros del sindicato quedan afiliados al partido" (Zuazo, 2010, p.126). Este mismo autor señala que "el MAS nace de las organizaciones sociales campesinas a partir de la decisión de estas de contar con un instrumento político para actuar en democracia; es decir, el MAS es, por su origen, un partido campesino" (Zuazo, 2010, p.121).

Estas cuestiones podrían plasmar algunas de las características mencionadas a lo largo del presente artículo en referencia a los movimientos sociales y los partidos políticos. Si bien los movimientos sociales tendrían cierta capacidad para adaptarse rápidamente a escenarios cambiantes y de protesta social, su no participación en procesos electorales podría lastrar dicho potencial de influir en la toma de decisiones en las instituciones estatales. No obstante, si los 
partidos políticos no son capaces de cooptar dichas demandas y a sus demandantes, bien los movimientos sociales podrían dar el salto a la competencia electoral bien podría producirse una deslegitimación de los partidos políticos más identificados por la sociedad con la situación de crisis. En cierto modo, la emergencia del MAS ejemplificaría esta pugna por la representación ciudadana y el liderazgo de las instituciones.

A este respecto, pero en la línea de los imaginarios colectivos y cosmovisiones que ya se han mencionado en capítulos previos, Quijano señala que

En Bolivia, la demanda de las poblaciones que precisamente fueron víctimas de estados no nacionales y no democráticos, es no tanto más nacionalismo y más Estado, sino ante todo otro Estado; esto es, des/colonializar ese Estado, que es la única forma de democratizarlo. (Quijano, 2006, p.21)

Entroncaría esta cuestión planteada por Quijano con la de representatividad y asunción de valores y simbologías de los colectivos que hasta entonces se podrían considerar subalternos. Estos son, los pueblos indígenas que desde la Colonia quedaron excluidos de los órganos de poder, tanto institucionales como simbólicos (Sicerone, 2015). La importancia de los significados, discursos y capacidad de representar a parte de la sociedad que se sentía excluida de su propio Estado, podría entenderse en la capacidad que Morales y el MAS desplegaron para defender en las protestas sociales de diversa índole sus demandas y para plasmar estos apoyos, en votos. Sirvan estas líneas de Archondo a modo de ejemplo:

La probada utilidad de las elecciones. A diferencia de lo que generalmente sucedía con la izquierda, el líder cocalero se benefició de ellas y demostró que un movimiento marginal puede salir del asedio cuando va ocupando gradualmente el Estado, aunque sea desde sus espacios periféricos. De pronto, la lucha en defensa de la coca quedaba reforzada por estructuras institucionales y fuentes estables de recursos. (Archondo, 2007, p.85)

Se entiende por tanto la importancia de la protesta y presentación de demandas desde vías no institucionales, las cuales pudieron otorgarle credibilidad ante una parte de sus futuros votantes: 
Desde 2000, en Bolivia, un partido que no contara con seguidores movilizados en las calles ya adolecía de una especie de cojera. Así, lejos de restringirse a la acción electoral, el MAS la incorporó a su repertorio de lucha. Estamos ante el cuarto y último componente de la conciencia de Evo Morales: la legalidad, aunque indispensable, no es suficiente. Cuando las limitaciones institucionales se hacían palpables, el movimiento activaba sus resortes extraparlamentarios para presionar y hacer avanzar la maquinaria estatal que aún le resultaba ajena. En esa dialéctica, el MAS se fue convirtiendo en un actor insustituible ya que contaba con una fuerza adicional más allá de su poder electoral. (Archondo, 2007, p.86)

Se mostraría pues que el MAS, partido de organizaciones sociales, planteó una doble batalla al Estado y restantes actores político pro statu quo: una en el medio urbano y rural, caracterizada por la protesta social, la alianza con otras organizaciones sociales y la demanda de cambios en las políticas públicas del Estado y sus imaginarios. Otra, por la vía electoral, entrando en estas mismas estructuras políticas que rechazaban o no eran capaces de asumir los cambios demandados por una porción creciente de la sociedad. Ambas, aparentemente, le permitieron tanto la asunción y presentación de demandas no asumidas por otros actores, como la capacidad para aglutinar, cooptar y generar visiones alternativas a las vigentes entonces. Llevó a cabo una traducción del cambio social al cambio institucional, cuestión que quedaría posteriormente significada en la Constitución Plurinacional de Bolivia de 2009 y en la asunción de nuevos valores y cosmovisiones para el Estado. Como se mencionó anteriormente, dejando atrás la concepción occidental y occidentalizante imperante desde la Colonia.

\section{Conclusiones}

Tras esta breve reflexión en torno a la acción colectiva en tiempos de crisis y tomando como referencia los movimientos sociales y los partidos políticos con la experiencia del MAS como telón de fondo, podría concluirse que, aparentemente, ante procesos de cambio, se abriría una ventana de oportunidad. Dicha posibilidad evidenciaría la debilidad de los partidos políticos, especialmente aquellos más conformes con el statu quo vigente, de adaptarse al cambio social en proceso. Asimismo, también podría mostrar una apreciable facilidad de los movimientos 
sociales para surgir y/o establecerse como vías de canalización y expresión de demandas no suficientemente cooptadas o defendidas desde las instituciones políticas del Estado.

Asimismo, no debiera olvidarse que la experiencia boliviana aquí presentada fue en cierto modo reflejo de políticas públicas implementadas desde unos gobiernos que trataron de imponer un modelo social, económico y político de marcado carácter neoliberal. La privatización de empresas públicas, la leve grabación impositiva a los recursos naturales extraídos o las políticas de austeridad en materia social, son elementos que ciertamente podrían ser conocidos en otras latitudes de la región y el mundo apenas unos años después. En este sentido, la resistencia social, así como el despliegue de un variado repertorio de acción y, sobre todo, la asunción de considerar a las vías electorales como cruciales para proponer otras lógicas de cambio, se mostraron de notable importancia. Aunque los gobiernos bolivianos tuvieron que dar marcha atrás en numerosas decisiones tras la reacción ciudadana, no fue hasta que variadas organizaciones sociales, sindicales, campesinas e indigenistas se unieron bajo el paraguas del MAS que se produjo una verdadera transformación socio-política del país. El sistema de partidos mutó por completo, por primera vez un indígena ocupaba la presidencia del país, y la nueva Constitución de 2009 redefinía al Estado tanto en elementos discursivos como de significados y políticas públicas a seguir.

Por tanto, debiera tomarse en consideración que ante ciertas coyunturas de crisis social, la ciudadanía a través de la protesta social y/o de la participación por vía electoral puede disputar los escenarios vigentes y propones alternativas. 


\section{Referencias Bibliográficas}

Archondo, R. (2007). La ruta de Evo Morales. Nueva Sociedad, o․ 209, mayojunio de 2007, 82-99.

Bravo, J. (2002). Partidos Políticos, Estado y Derecho: de la Hostilidad a la Teoría. Anales de la Facultad de Derecho, oㅜ 19, diciembre de 2002, 73-93.

Boudon, L. (1996). Hacia una teoría sobre nuevos partidos políticos. Colombia Internacional, № 35, julio - Septiembre de 1996, 28-38.

Cabezas, M. (2007). Caracterización del Ciclo Rebelde: 2000-2005. Bolivia en movimiento: acción colectiva y poder político. Jesús Espasandín López y Pablo Iglesias Turrión (editores). Madrid: El Viejo Topo.

Cotler, J. (2005). Bolivia-Ecuador-Perú, 2003-2004: ¿tempestad en los Andes? Documento de Trabajo: área América Latina, noviembre, número 51. Real Instituto Elcano: Madrid.

Daza, J. (2014). Partidos y Partidismo. Los partidos políticos colombianos y su enraizamiento en la sociedad. Revista Facultad De Derecho y Ciencias Políticas, Vol. 44, Núm. 120, 311-347, enero-junio de 2014. Medellín (Colombia)

Duverger, M. (2002). Los Partidos Políticos. Madrid: Fondo De Cultura Económica de España.

Caren, N. (2007). Political Process. Blackwell Encyclopedia of Sociology. George Ritzer. Oxford: Blackwell Publishing.

Espinoza, C. y Gozálvez, G. (2003). Bolivia arrinconada en la azotea de su historia. OSAL: Observatorio Social de América Latina, Año IV, no 10, enero-abril de 2003. Buenos Aires: CLACSO.

Estrada, S. (2015). Reflexiones sobre la reforma laboral mexicana. Collectivus, Revista de Ciencias Sociales, Vol. 2, Núm.1, 97-122.

García, J. y Rodríguez, P. (2015). La identidad y lo popular: la identidad popular en tiempos de socialismo. Collectivus, Revista de Ciencias Sociales, Vol. 2, Núm.1, 439.

Ibarra, P. (2005). Manual de sociedad civil y movimientos sociales. Madrid: Editorial Síntesis.

Mcadam, D. (1982). Political Process and the Development of the Black Insurgency: 1930-1970. Chicago: The University of Chicago Press

Perreault, T. (2006). From the Guerra del Agua to the Guerra del Gas: resource governance, neoliberalism and popular protest in Bolivia. Antipode, a radical journal of geography, Vol. 38, 150-172, enero de 2006. Reino Unido: Antipode Foundation.

Quijano, A. (2006). Estado-nación y movimientos indígenas en la región Andina: cuestiones abiertas. OSAL, Observatorio Social de América Latina, año VI no 19, enero-abril de 2006. CLACSO: Buenos Aires.

Rose, R. y Mackie, T. (1988). Do parties persist or fail? The big trade-off facing 
organizations. When parties fail: emerging alternative organization. Kay Lawson y Peter H. Merkl. Princeton: Princeton UniversityPress

Sicerone, D. (2015). El marxismo des-colonizado como detracción a la crítica de Popper al historicismo. Collectivus Revista de Ciencias Sociales, Vol. 2, Núm.2, 134-160.

Stokes, S. (2006). Partidos Políticos y Democracia. Annual Review of Political Science, Volumen 2 de 1999.

Suvelza, FX.(2007). ¿Cómo moderar el péndulo boliviano? De las privatizaciones a la recuperación del Estado. Nueva Sociedad, №. 207, enero-febrero, pp. 144157. Buenos Aires: Friedrich Ebert Stiftung.

Tarrow, S. (1998). El poder en movimiento los movimientos sociales, la acción colectiva. Madrid: Editorial Alianza

Vela, JP. (2008). Gobernabilidad y partidos políticos después del 2006. Revista Política Interior, Vol. 1, № 2, diciembre de 2008.

Ventura, F. (2007). Movimientos sociales y partidos políticos en América Latina: una relación cambiante y compleja. Política y Cultura, primavera 2007, ํㅡ 27, 3153.

Zuazo, M. (2010). ¿Los movimientos sociales en el poder? El gobierno del MAS en Bolivia. Nueva Sociedad, no. 227, mayo-junio de 2010.

\section{Para citar este artículo:}

García, I. (2016). Movimientos sociales y partidos políticos ante procesos de cambio: un debate teórico a la luz de la emergencia del Mas. Collectivus, Revista de Ciencias Sociales, 3(2), 11-36. doi: http://dx.doi.org/10.15648/Coll.2.2016.2 